\title{
A Personal Account on Industrial Collaborations in the Field of $\mathrm{C}-\mathrm{H}$ Activation
}

\author{
Olivier Baudoin*
}

\begin{abstract}
In recent years, transition-metal-catalyzed C-H functionalization has emerged as a potentially greener alternative to classic cross-couplings and as a powerful tool to access complex functional molecules with improved step-economy. This short account relates our experience of industrial collaborations in $\mathrm{C}\left(\mathrm{sp}^{3}\right)-\mathrm{H}$ bond activation, which were key to the development of this topic in our group. The synthesis of the antianginal drug Ivabradine led us to develop a general approach to benzocyclobutenes, which were further employed in pericyclic reactions. A follow-up study led us to discover a new method to construct arylcyclopropanes via double C-H activation and the coupling of two alkyl groups. Finally, targeting the herbicide Indaziflam contributed to develop $\mathrm{C}\left(\mathrm{sp}^{3}\right)-\mathrm{H}$ activation as a powerful tool to access a variety of relevant indane motifs. We hope that these successful stories will help to stimulate further fruitful Industry-Academia collaborations in the field of synthetic chemistry.
\end{abstract}

Keywords: Bioactive molecules $\cdot \mathrm{C}-\mathrm{H}$ activation $\cdot$ Catalysis $\cdot$ Palladium

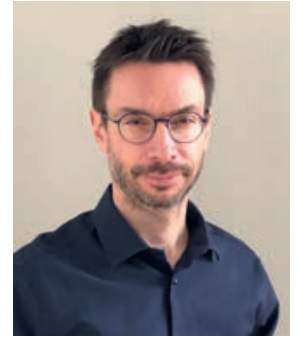

Olivier Baudoin obtained his $\mathrm{PhD}$ degree in 1998 under the supervision of Prof. J.-M. Lehn and Dr. M.-P. Teulade-Fichou at Collège de France, Paris. After a post-doc with K. C. Nicolaou at the Scripps Research Institute, La Jolla (USA), he was recruited as CNRS researcher at the Institut de Chimie des Substances Naturelles (France) in 1999, where he became a group leader in 2004. In 2006, he was appointed as Professor at the University of Lyon and since 2015 he has been a Full Professor at the University of Basel (Switzerland). He received the CNRS Bronze Medal in 2005, the Young Professor Award from the French Chemical Society, Organic Chemistry Division in 2010, and was a Junior Member of the Institut Universitaire de France from 2009-2014. His current research focuses on the development of new methods for the functionalization of $\mathrm{C}-\mathrm{H}$ bonds and their application to complex molecule synthesis.

\section{Introduction}

Metal-catalyzed cross-coupling methods such as the Nobel Prize-winning Negishi and Suzuki-Miyaura reactions, ${ }^{[1]}$ which emerged in the late 1970s, are still the golden standards for the formation of $\mathrm{C}-\mathrm{C}$ bonds at production scales. ${ }^{[2]}$ These reactions are reliable and widely applicable, but produce significant metal waste and require the use of two functionalized precursors, including a stoichiometric main-group organometallic reagent. In addition to improving on these well-established reactions, there is an increasing pressing need to develop disruptive catalytic technologies that would offer shorter and more sustainable synthetic routes towards functional organic molecules. In the past two decades, metal-catalyzed $\mathrm{C}-\mathrm{H}$ bond activation and functionalization has emerged as a powerful and potentially greener alternative to traditional cross-couplings to generate a variety of $\mathrm{C}-\mathrm{C}$ and

*Correspondence: Prof. Dr. O. Baudoin, E-mail: olivier.baudoin@unibas.ch, University of Basel, Department of Chemistry, St. Johanns-Ring 19, $\mathrm{CH}-4056$ Basel, Switzerland carbon-heteroatom bonds. ${ }^{[3]}$ This research field has witnessed a spectacular expansion in the last two decades, fueled by the development of new efficient catalysts and ligands. A vast array of synthetic methods has been developed and some of these have been adapted on multi-kg scales in process chemistry departments of various pharmaceutical companies. ${ }^{[4-6]}$ In addition, these methods are increasingly employed in the highly demanding context of natural product synthesis, ${ }^{[7-9]}$ and in medicinal chemistry programs. ${ }^{[10]}$ This perspective reflects on industrial collaborations in the field of $\mathrm{C}-\mathrm{H}$ activation, which had a significant impact on our group's research program.

\section{Ivabradine: From Benzocyclobutenes to Cyclopropanes}

Ivabradine (1) is an antianginal drug manufactured by Servier, used for the symptomatic management of stable heart-related chest pain and heart failure which are not fully managed by beta blockers (Fig. 1). ${ }^{[11,12]}$ It is composed of benzocyclobutene (BCB) and tetrahydrobenzoazepinone fragments linked by an alkylamine tether.<smiles>COc1cc2c(cc1OC)CC(=O)N(CCCN(C)C[C@@H]1Cc3cc(OC)c(OC)cc31)CC2</smiles>

Ivabradine (1)

Fig. 1. Structure of Ivabradine.

In 2003, we reported a new method to access olefins 3 and BCBs 4 from aryl halides 2 by palladium $(0)$-catalyzed $\mathrm{C}\left(\mathrm{sp}^{3}\right)-\mathrm{H}$ activation (Scheme 1). ${ }^{[13]}$ Depending on the nature of the alkyl group undergoing $\mathrm{C}-\mathrm{H}$ activation, $\beta-\mathrm{H}$ elimination or reductive elimination provided products $\mathbf{3}$ and $\mathbf{4}$, respectively. The use of a very bulky ligand $\left[\mathrm{P}(o \text {-tol })_{3}\right.$, aka TOTP] was found to be optimal in this initial study. In subsequent work, the formation of olefins 
(3) was further optimized and developed, ${ }^{[14]}$ and its mechanism was investigated. ${ }^{[15]}$ In parallel, Dr. Jean-Louis Peglion at Servier became interested in the synthesis of the BCB motif in Ivabradine by using this new methodology, and we initiated a collaborative program to further study the potential of this reaction.<smiles>[R]CC([R])(c1ccccc1[X])C([R])C</smiles>

2

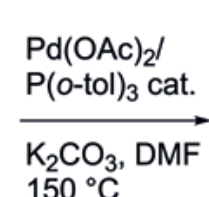
$150{ }^{\circ} \mathrm{C}$

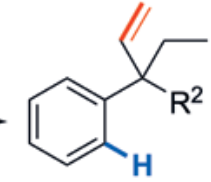

3

$\left(\mathrm{R}^{1}=\mathrm{Me}\right)$ or<smiles>[R]C1(C)Cc2ccccc21</smiles>

4

Scheme 1. Synthesis of olefins and benzocyclobutenes by $\mathrm{Pd}^{0}$-catalyzed $\mathrm{C}\left(\mathrm{sp}^{3}\right)-\mathrm{H}$ activation.

\subsection{Synthesis of Benzocyclobutenes}

We first re-optimized the reaction leading to BCBs (6) from aryl bromides (5, Scheme 2$)$. The combination of a bulky trialkylphosphine ligand, $\mathrm{P}(t-\mathrm{Bu})_{3}$, with potassium carbonate in a polar solvent (DMF) provided good yields across a broad range of examples. ${ }^{[16]}$ One major limitation was, however, the requirement for a quaternary benzylic position $\left(\mathrm{R}^{1}, \mathrm{R}^{2} \neq \mathrm{H}\right)$ to successfully produce the $\mathrm{BCB}$ product. Indeed, in the presence of a tertiary benzylic position $\left(\mathrm{R}^{1}\right.$ or $\left.\mathrm{R}^{2}=\mathrm{H}\right)$, styrene products were mainly obtained and could not be avoided. Since Ivabradine possesses such a tertiary carbon, we provided an indirect solution by first forming $\mathrm{BCBs}$ with a gem-diester group and performing a subsequent decarboxylation. In particular, BCB 6a could be employed as precursor to the active ingredient following this $\mathrm{C}-\mathrm{H}$ activation/decarboxylation strategy. ${ }^{[17]}$ However, the moderate yield of the $\mathrm{C}-\mathrm{H}$ activation step for this particular example, together with the relatively high catalyst loading, prevented the scalability of this method and its use in a production context.

In parallel, we investigated the reaction mechanism and detailed DFT calculations were performed by Dr. Eric Clot at the<smiles></smiles>

5
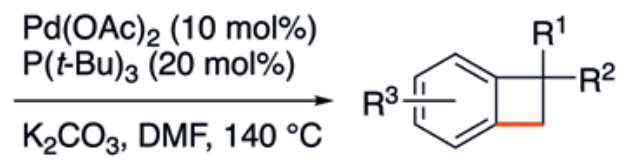

6

27 examples up to $92 \%$ yield<smiles>COc1cc2c(cc1OC)C(C(C)=O)(C(C)=O)C2</smiles>

$6 a(44 \%)$

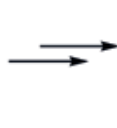

Ivabradine (1)

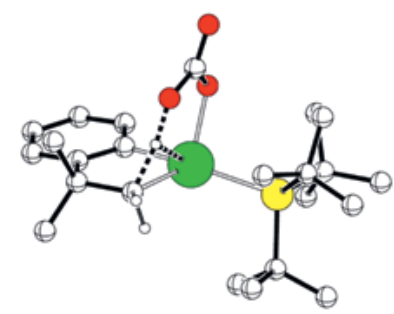

computed $\mathrm{C}-\mathrm{H}$ activation transition state

$\left[R^{1}=R^{2}=\mathrm{Me}, \mathrm{R}^{3}=\mathrm{H}\right.$; ligand $=\mathrm{P}(t-\mathrm{Bu})_{3}$; base $\left.=\mathrm{CO}_{3}{ }^{2-}\right]$

Scheme 2. Synthesis of BCBs by $\mathrm{Pd}^{0}$-catalyzed $\mathrm{C}\left(\mathrm{sp}^{3}\right)-\mathrm{H}$ arylation.

University of Montpellier. In particular, the now well-established 'concerted metallation-deprotonation' (CMD) mechanism ${ }^{[18]}$ was proposed, with carbonate as the active base cleaving the $\mathrm{C}-\mathrm{H}$ bond (Scheme 2, bottom). Of note, carbonate was shown to be a competent base in the absence of other bases such as acetate or pivalate. Later, a more detailed DFT study compared the effect of different ligands and bases, and showed that these components may favor different $\mathrm{C}-\mathrm{H}$ activation geometries. ${ }^{[19,20]}$ The formation of BCBs was also extended to aryl chloride reactants, which are usually cheaper and more available than the corresponding bromides, employing similar reaction conditions. [21]

$\mathrm{BCB}$ are not only interesting strained benzenoid motifs for medicinal chemistry, but also useful building blocks in organic synthesis. ${ }^{[22]}$ Indeed, they undergo thermal $4 \pi$-electrocyclic ringopening, giving rise to $o$-quinodimethanes that may participate in further pericyclic reactions such as Diels-Alder cycloadditions. This property was exploited by combining the BCBs generated by $\mathrm{C}\left(\mathrm{sp}^{3}\right)-\mathrm{H}$ arylation (6) with a variety of activated dienophiles under microwave irradiation (Scheme 3). ${ }^{[23]}$ The corresponding cycloadducts 7 were obtained with a high diastereoselectivity, reflecting both the torquoselectivity of the $4 \pi$-electrocyclic ringopening and the endo cycloaddition mode.
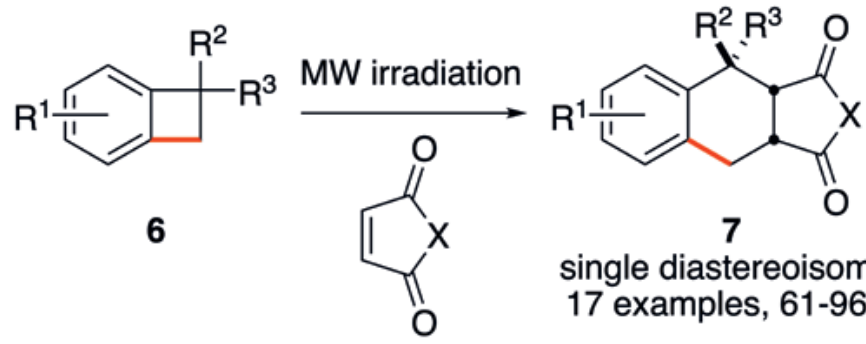

single diastereoisomer 17 examples, $61-96 \%$

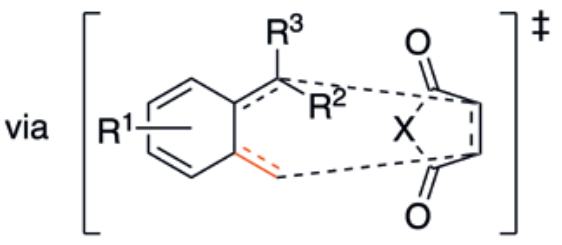

Scheme 3. Application of C-H activation-generated BCBs in Diels-Alder cycloadditions.

In addition, $\mathrm{C}-\mathrm{H}$ activation-generated $\mathrm{BCBs}$ were exploited in electrocyclic cascades to generate 3,4-dihydroisoquinolines, ${ }^{[24]}$ and an application of this methodology is shown in Scheme 4. BCB $6 \mathbf{b}$ was converted to imine $\mathbf{6 d}$ via hydrolysis, Curtius rearrangement (leading to amine $\mathbf{6 c}$ ) and condensation. Upon heating in DMF at $160{ }^{\circ} \mathrm{C}$, $6 \mathbf{d}$ underwent a $4 \pi$-electrocyclic ringopening/6 $\pi$-electrocyclization cascade to yield 3,4-dihydroisoquinoline 9 via the putative $o$-quinodimethane intermediate $\mathbf{8}$. Compound 9 was then converted to the tetrahydroprotoberberine alkaloid coralydine (10) in three steps.

In conclusion, the collaboration with Servier allowed us to study this $\mathrm{C}-\mathrm{H}$ activation approach to BCBs in great detail, pushing us to explore medicinally relevant examples, and leading us to further exploit the rich chemistry of these molecules in multi-step synthesis.

\subsection{Synthesis of Cyclopropanes}

A couple of years ago, we initiated a follow-up collaboration with the process chemistry group (ORIL) of Servier, including Drs. Maxime Gicquel, Alexandre Le Flohic, Jean Fournier and Rodolphe Tamion, to revisit the $\mathrm{C}-\mathrm{H}$ activation-based approach to $\mathrm{BCBs}$ in light of recent advances in the field. These investiga- 


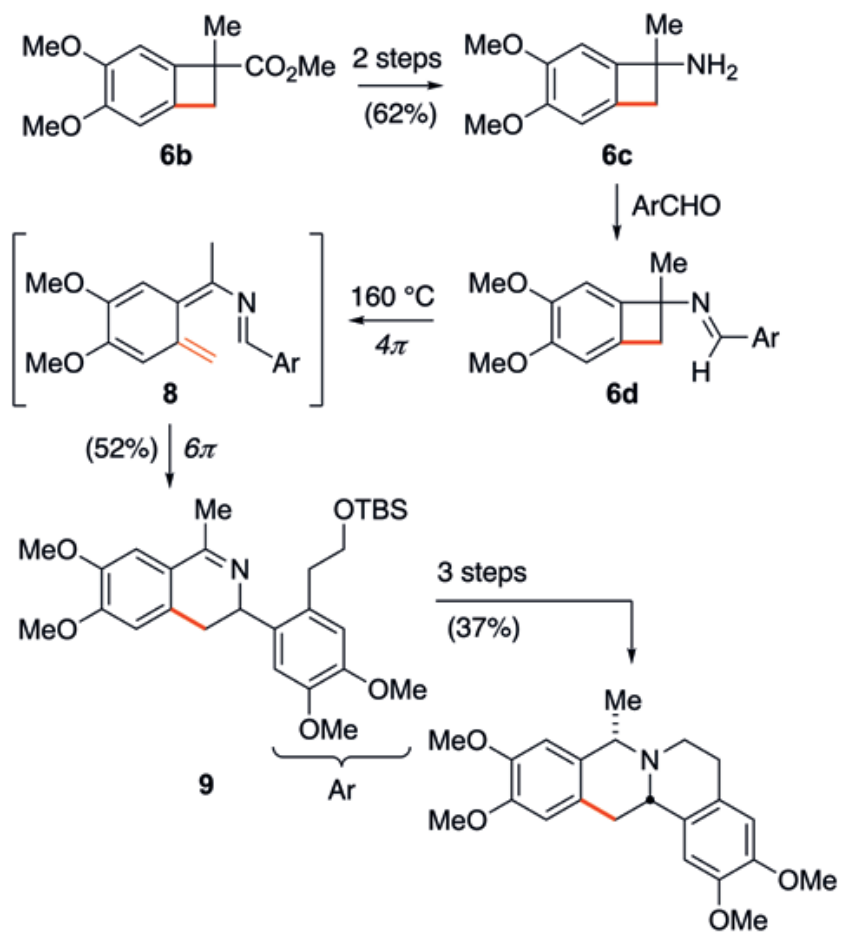

( \pm -coralydine (10)

Scheme 4. Application of $\mathrm{C}-\mathrm{H}$ activation-generated BCBs to the synthesis of coralydine.

tions led us to reconsider the effect of the base and ligand in the formation of BCB $\mathbf{6 e}$ from prototypical aryl bromide $\mathbf{5 e}$ (Scheme 5). Using $\mathrm{Pd}\left(\mathrm{PPh}_{3}\right)_{4}$ as the catalyst and potassium carbonate as the base, BCB 6e was exclusively observed (entry 1), in agreement with our previous work (see Scheme 2). However, when carbonate was replaced with pivalate (entry 2), the selectivity completely switched to the formation of cyclopropane 11e, arising from double $\mathrm{C}-\mathrm{H}$ activation and $\mathrm{C}-\mathrm{C}$ coupling at the geminal methyl groups. Replacing $\mathrm{PPh}_{3}$ with $\mathrm{P}(t-\mathrm{Bu})_{3}$ yielded a mixture of 6e and 11e, consistent with previous findings on the role of bulky ligands to favor the BCB product (see Scheme 2). Given the great interest in arylcyclopropanes in medicinal chemistry, ${ }^{[25]}$ these observations led us to further optimize this new cyclopropanation reaction, and to investigate the reaction mechanism.[26]

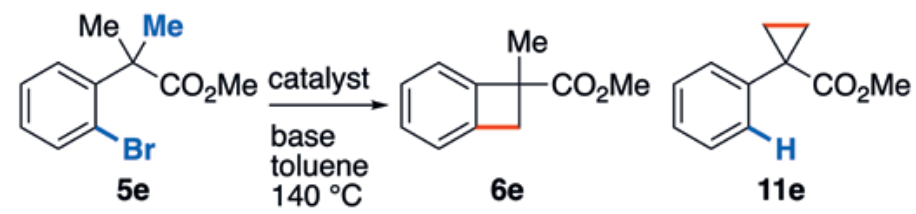

\begin{tabular}{lllll} 
entry & catalyst (10 mol\% $\mathrm{Pd})$ & base (2 equiv) & $6 \mathrm{e}(\%)^{[\mathrm{a}]}$ & $\mathbf{1 1 e}(\%)^{[\mathrm{a}]}$ \\
\hline 1 & $\mathrm{Pd}\left(\mathrm{PPh}_{3}\right)_{4}$ & $\mathrm{~K}_{2} \mathrm{CO}_{3}$ & 46 & 0 \\
2 & $\mathrm{Pd}\left(\mathrm{PPh}_{3}\right)_{4}$ & KOPiv & 0 & 75 \\
3 & $\mathrm{Pd}_{2} \mathrm{dba}_{3} / \mathrm{P}(t-\mathrm{Bu})_{3}$ & KOPiv & 36 & 22
\end{tabular}

Scheme 5. Influence of the base and ligand on the formation of BCB vs cyclopropane. [a]NMR yield.

The optimized conditions employed the standard, commercially available $\mathrm{Pd}\left(\mathrm{PPh}_{3}\right)_{4}$ catalyst $(10 \mathrm{~mol} \%)$ and stoichiometric potassium pivalate as the base in a toluene/DMSO mixture (95:5) at $120-140{ }^{\circ} \mathrm{C}$ (Scheme 6), and produced a range of arylcyclopropanes in moderate to excellent yield. The cyclopropane ring was either generated from the coupling of two methyl groups $\left(R^{1}=R^{2}\right.$
$=\mathrm{H})$, one methyl and one activated methylene $\left(\mathrm{R}^{1}=\mathrm{H}, \mathrm{R}^{2}=\right.$ ester or nitrile), or two activated methylene groups. Stoichiometric studies with isolated palladium complexes shed light on the different $\mathrm{Pd}$ intermediates formed during this reaction. In particular, a first $\mathrm{C}-\mathrm{H}$ activation step produces five-membered palladacycle 12 and pivalic acid via the CMD mechanism. Then compound 12 undergoes reversible ring-opening via protonation with pivalic acid to form the $\sigma$-alkylpalladium complex 13 , which undergoes a second pivalate-mediated $\mathrm{C}-\mathrm{H}$ activation to give the high-energy four-membered palladacycle 14. The latter yields cyclopropane $11 f$ upon reductive elimination. Using carbonate as the base, the second $\mathrm{C}-\mathrm{H}$ activation $(\mathbf{1 3} \rightarrow \mathbf{1 4})$ does not occur (for a reason which is yet unclear) and BCB $\mathbf{6} \mathbf{f}$ is formed instead by reductive elimination from 12 .
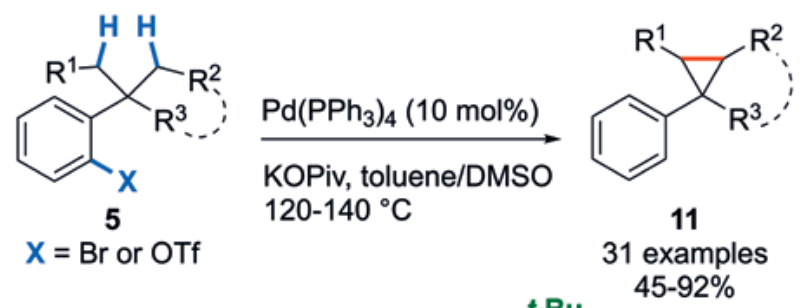<smiles>CP1CC(C)(C)c2ccccc21</smiles>

12<smiles>CC1(C)Cc2ccccc21</smiles>

$6 f$<smiles></smiles>

13<smiles>CC1CC1(C)c1ccccc1</smiles>

$11 f$
Scheme 6. Synthesis of arylcyclopropanes by double $\mathrm{C}\left(\mathrm{sp}^{3}\right)-\mathrm{H}$ activation.

To demonstrate its potential utility, we applied this method to the synthesis of the anti-insomnia drug Lemborexant (15, Scheme 7). $\gamma$-Lactone $\mathbf{5 g}$ was obtained in five steps using classic chemistry. Application of the standard conditions to $\mathbf{5 g}$ provided fused cyclopropane 11g, arising from the coupling of the highlighted methyl and activated methylene groups. Then a ring-opening amidation with 2-amino-5-fluoropyridine and a Mitsunobu reaction furnished target molecule $\mathbf{1 5}$. This application demonstrates the suitability of this new double $\mathrm{C}-\mathrm{H}$ activation-based reaction to generate polysubstituted cyclopropanes. This work stimulated further exploitation of the 1,4-Pd shift strategy to functionalize remote alkyl positions via amino- and alkoxycarbonylation. ${ }^{\text {[27] }}$ Overall, this follow-up collaboration was key to uncover new reactivity, push the reaction to its limits and inspire further developments.

\section{Indaziflam}

After our initial studies on the synthesis of BCBs, we and others were able to generalize the intramolecular $\mathrm{C}\left(\mathrm{sp}^{3}\right)-\mathrm{H}$ arylation reaction to construct diverse fused 5-membered rings. [14,20,21,28-30] In particular, we showed that aryl bromide 16, containing geminal isopropyl groups, undergoes selective $\mathrm{C}-\mathrm{H}$ arylation at one methyl group in the presence of a fluorinated analogue of TOTP to provide indane $\mathbf{1 7}$ as a single diastereoisomer (Scheme 8). [14] The trans relationship between the two largest groups (isopropyl and methyl) presumably reflects the minimization of strain at the 
<smiles>CC1(c2cc(F)ccc2Br)COC(=O)C1</smiles>

$5 g$

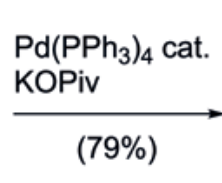

$(79 \%)$

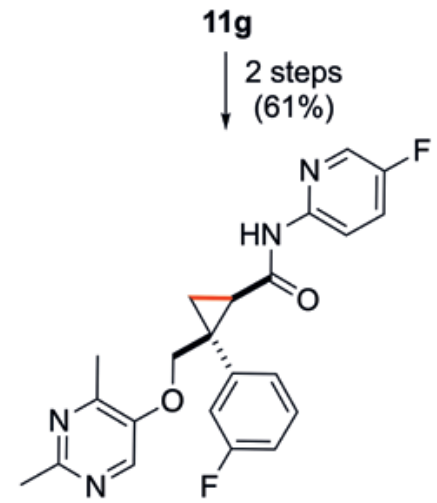

( \pm )-Lemborexant (15)
Scheme 7. Application of the new cyclopropanation reaction to the synthesis of Lemborexant (15).

$\mathrm{C}-\mathrm{H}$ activation transition state. This work was generalized to aryl chloride reactants, ${ }^{[21]}$ and an enantioselective version was later developed. ${ }^{[31,32]}$<smiles>CC(C)C(C#N)(c1ccccc1Br)C(C)C</smiles>

16

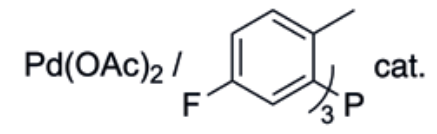

$\mathrm{K}_{2} \mathrm{CO}_{3}, \mathrm{DMF}, 100^{\circ} \mathrm{C}$

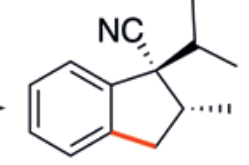

17
$50 \%$, d.r. $>98: 2$

Scheme 8. First synthesis of indanes by $\mathrm{C}\left(\mathrm{sp}^{3}\right)-\mathrm{H}$ arylation.

1-Indanols and 1-indanamines are important substructures in bioactive molecules such as drugs, fragrances and agrochemicals. ${ }^{[33]}$ In 2012, we initiated a collaboration with Drs. Mark Ford and Jean-Pierre Vors at Bayer CropScience to study the access to this company's major herbicide Indaziflam (18) using the $\mathrm{C}\left(\mathrm{sp}^{3}\right)-\mathrm{H}$ arylation methodology (Scheme 9). The optimized reaction conditions to generate a range of protected 1-indanols and 1-indanamines $\mathbf{2 0}$ from aryl bromides $\mathbf{1 9}$ included the use of simple $\mathrm{PPh}_{3}$ as the ligand and catalytic PivOK/stoichiometric $\mathrm{K}_{2} \mathrm{CO}_{3}$ as the basic system. ${ }^{[34]}$ Interestingly, protected indanols $\left[\right.$ e.g. $\left.\mathrm{Y}=\mathrm{OSi}\left(i-\mathrm{Pr}_{3}\right)\right]$ and indanamines $($ e.g. $\mathrm{Y}=\mathrm{NPhth})$ provided opposite diastereoselectivities in the arylation of an isopropyl group $\left(\mathrm{R}^{1}=\mathrm{Me}, \mathrm{R}^{2}=\mathrm{H}\right)$, with the former giving the cis and the latter the trans major diastereoisomer. This result was ascribed to the shape of the Y substituent, with parasol-shaped silyloxy and wallshaped phthalimido groups leading to different conformations at the $\mathrm{C}-\mathrm{H}$ activation transition state. This method was employed to access 1-indanamine $\mathbf{2 0 b}$, which is a known intermediate in the synthesis of Indaziflam. ${ }^{[35]}$ Compound 20a was obtained on a gram scale by $\mathrm{C}\left(\mathrm{sp}^{3}\right)-\mathrm{H}$ arylation in moderate yield $(55 \%)$ but as a single trans diastereoisomer. Interestingly, the yield reflected the degree of substitution of the alkyl group undergoing $\mathrm{C}-\mathrm{H}$ activation. For instance, with an additional methyl group $\left(\mathrm{R}^{1}=\mathrm{R}^{2}=\mathrm{Me}\right)$ the yield increased to $86 \%$. A standard deprotection of the amino group with hydrazine provided the free amine $\mathbf{2 0 b}$ as a racemic mixture. Of note, this synthetic route does not allow to control the absolute configuration of the target, but the relative configuration is fully controlled in the $\mathrm{C}-\mathrm{H}$ activation step. This collaboration allowed the further development of the ring-forming $\mathrm{C}\left(\mathrm{sp}^{3}\right)-\mathrm{H}$ activation ${ }^{[30]}$ and the demonstration of its relevance to access important functional molecules. Following up on this work, we recently reported the enantioselective synthesis of indane-containing sesquiterpene natural products, ${ }^{[36,37]}$ and the enantioselective synthesis of indanes by $\mathrm{C}-\mathrm{H}$ arylation of methylenes. ${ }^{[38]}$<smiles>[Y]C(c1cc[R19]([H])cc1Br)C([R])([R])C</smiles>

19

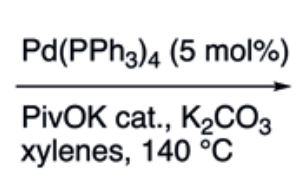
xylenes, $140^{\circ} \mathrm{C}$

$\mathrm{Y}=\mathrm{OR}, \mathrm{NR}_{2}$<smiles>Cc1ccc2c(c1)[C@H](c1ccccc1)C(C)C2</smiles>

20a $(55 \%)$

d.r. $>98: 2$

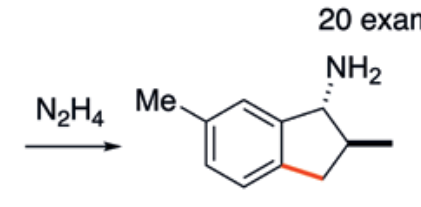

( \pm )-20b (98\%)

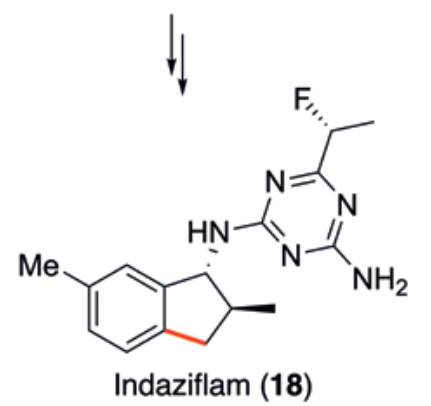

Scheme 9. Synthesis of 1-indanols and 1-indanamines and application to the synthesis of Indaziflam (18).

\section{Conclusions}

Industrial collaborations were instrumental to the development of our $\mathrm{C}-\mathrm{H}$ activation program, and will hopefully continue to do so in the years to come. They were an invaluable source of inspiration and exposed us to new perspectives, pushing us to explore other aspects such as scalability, safety and compatibility with specific functional groups, which we would not have otherwise considered. In addition, in the examples reported herein, we were given the freedom to explore reactions in a comprehensive manner, investigate their mechanism and accumulate sufficient data for publication. We hope that these win-win case studies will help to stimulate further Industry-Academia interactions.

\section{Acknowledgements}

The experimental work was performed by Dr. Nicolas Audic, Dr. Riccardo Piccardi, Dr. Manon Chaumontet, Dr. Antonin Clemenceau, Dr. Pierre Thesmar, and Dr. Simon Janody, to whom I express my gratitude. I also thank scientists at Servier, ORIL and Bayer Cropscience, already cited in this article, for their open-mindedness and support of these research programs. Many thanks to the IP services at the University of Lyon and University of Basel for their efforts in establishing the collaboration contracts.

Received: March 9, 2021

[1] 'Metal-Catalyzed Cross-Coupling Reactions and More', Eds. A. de Meijere, S. Bräse, M. Oestreich, Wiley-VCH, Weinheim, Germany, 2014, Vol. 1-3.

[2] 'Transition Metal-Catalyzed Couplings in Process Chemistry', Eds. J. Magano, J. R. Dunetz, Wiley-VCH, Weinheim, Germany, 2013.

[3] J. F. Hartwig, J. Am. Chem. Soc. 2016, 138, 2, https://doi.org/10.1021/jacs.5b08707. 
[4] M. Cameron, B. S. Foster, J. E. Lynch, Y.-J. Shi, U.-H. Dolling, Org. Proc. Res. Dev. 2006, 10, 398, https://doi.org/10.1021/op050217j.

[5] S. G. Ouellet, A. Roy, C. Molinaro, R. Angelaud, J.-F. Marcoux, P. D. O'Shea, I. W. Davies, J. Org. Chem. 2011, 76, 1436, https://doi.org/10.1055/s-0030-1259889.

[6] R. J. Fox, N. L. Cuniere, L. Bakrania, C. Wei, N. A. Strotman, M. Hay, D. Fanfair, C. Regens, G. L. Beutner, M. Lawler, P. Lobben, M. C. Soumeillant, B. Cohen, K. Zhu, D. Skliar, T. Rosner, C. E. Markwalter, Y. Hsiao, K. Tran, M. D. Eastgate, J. Org. Chem. 2019, 84, 4661, https://doi.org/10.1021/acs.joc.8b02383.

[7] R. R. Karimov, J. F. Hartwig, Angew. Chem., Int. Ed. 2018, 57, 4234, https://doi.org/10.1002/anie.201710330.

[8] D. J. Abrams, P. A. Provencher, E. J. Sorensen, Chem. Soc. Rev. 2018, 47, 8925, https://doi.org/10.1039/C8CS00716K

[9] O. Baudoin, Angew. Chem. Int. Ed. 2020, 59, 17798 , https://doi.org/10.1002/anie.202001224.

[10] E. J. E. Caro-Diaz, M. Urbano, D. J. Buzard, R. M. Jones, Bioorg. Med. Chem. Lett. 2016, 26, 5378, https://doi.org/10.1016/j.bmcl.2016.06.036.

[11] J.-C. Tardif, I. Ford, M. Tendera, M. G. Bourassa, K. Fox, Eur. Heart J. 2005, 26, 2529, https://doi.org/10.1093/eurheartj/ehi586.

[12] W. Ruzyllo, M. Tendera, I. Ford, K. M. Fox, Drugs 2007, 67, 393, https://doi.org/10.2165/00003495-200767030-00005.

[13] O. Baudoin, A. Herrbach, F. Guéritte, Angew. Chem. Int. Ed. 2003, 42, 5736, https://doi.org/10.1002/anie.200352461.

[14] J. Hitce, P. Retailleau, O. Baudoin, Chem. Eur. J. 2007, 13, 792, https://doi.org/10.1002/chem.200600811

[15] C. E. Kefalidis, M. Davi, P. M. Holstein, E. Clot, O. Baudoin, J. Org. Chem. 2014, 79, 11903, https://doi.org/10.1021/jo501610x.

[16] M. Chaumontet, R. Piccardi, N. Audic, J. Hitce, J.-L. Peglion, E. Clot, O. Baudoin, J. Am. Chem. Soc. 2008, 130, 15157, https://doi.org/10.1021/ja805598s.

[17] J.-L. Peglion, O. Baudoin, N. Audic, M. Chaumontet, R. Piccardi, Laboratoires Servier - CNRS - Université Claude Bernard Lyon 1, FR20080004061, WO2010007253, 2010.

[18] L. Ackermann, Chem. Rev. 2011, 111, 1315, https://doi.org/10.1021/cr100412j.

[19] C. E. Kefalidis, O. Baudoin, E. Clot, Dalton Trans. 2010, 39, 10528 https://doi.org/10.1039/C0DT00578A

[20] See also: M. Lafrance, S. I. Gorelsky, K. Fagnou, J. Am. Chem. Soc. 2007, 129, 14570, https://doi.org/10.1021/ja076588s.

[21] S. Rousseaux, M. Davi, J. Sofack-Kreutzer, C. Pierre, C. E. Kefalidis, E. Clot, K. Fagnou, O. Baudoin, J. Am. Chem. Soc. 2010, 132, 10706 https://doi.org/10.1021/ja1048847.

[22] A. K. Sadana, R. K. Saini, W. E. Billups, Chem. Rev. 2003, 103, 1539 , https://doi.org/10.1021/cr010022j.
[23] M. Chaumontet, P. Retailleau, O. Baudoin, J. Org. Chem. 2009, 74, 1774, https://doi.org/10.1021/jo802471u.

[24] M. Chaumontet, R. Piccardi, O. Baudoin, Angew. Chem. Int. Ed. 2009, 48 , 179, https://doi.org/10.1002/anie.200804444.

[25] T. T. Talele, J. Med. Chem. 2016, 59, 8712 https://doi.org/10.1021/acs.jmedchem.6b00472.

[26] A. Clemenceau, P. Thesmar, M. Gicquel, A. Le Flohic, O. Baudoin, J. Am. Chem. Soc. 2020, 142, 15355, https://doi.org/10.1021/jacs.0c05887.

[27] T. Carný, R. Rocaboy, A. Clemenceau, O. Baudoin, Angew. Chem. Int. Ed. 2020, 59, 18980, https://doi.org/10.1002/anie.202007922.

[28] H. Ren, P. Knochel, Angew. Chem. Int. Ed. 2006, 45, 3462 https://doi.org/10.1002/anie.200600111.

[29] T. Watanabe, S. Oishi, N. Fujii, H. Ohno, Org. Lett. 2008, 10, 1759 , https://doi.org/10.1021/ol800425z.

[30] For an account: O. Baudoin, Acc. Chem. Res. 2017, 50, 1114 https://doi.org/10.1021/acs.accounts.7b00099.

[31] N. Martin, C. Pierre, M. Davi, R. Jazzar, O. Baudoin, Chem. Eur. J. 2012, 18, 4480, https://doi.org/10.1002/chem.201200018.

[32] P. M. Holstein, M. Vogler, P. Larini, G. Pilet, E. Clot, O. Baudoin, ACS Catal. 2015, 5, 4300, https://doi.org/10.1021/acscatal.5b00898.

[33] B. Gabriele, R. Mancuso, L. Veltri, Chem. Eur. J. 2016, 22, 5056 , https://doi.org/10.1002/chem.201503933.

[34] S. Janody, R. Jazzar, A. Comte, P. M. Holstein, J.-P. Vors, M. J. Ford, O. Baudoin, Chem. Eur. J. 2014, 20, 11084 , https://doi.org/10.1002/chem.201402907.

[35] M. Ford, J.-P. Vors, O. Baudoin, S. Janody, Bayer CropScience - CNRS Université Claude Bernard Lyon 1, WO2015113903, 2015.

[36] R. Melot, M. V. Craveiro, T. Bürgi, O. Baudoin, Org. Lett. 2019, 21, 812 https://doi.org/10.1021/acs.orglett.8b04086.

[37] R. Melot, M. V. Craveiro, O. Baudoin, J. Org. Chem. 2019, 84, 12933 , https://doi.org/10.1021/acs.joc.9b01669.

[38] R. Melot, M. Zuccarello, D. Cavalli, N. Niggli, M. Devereux, T. Bürgi, O. Baudoin, Angew. Chem. Int. Ed. 2021, 60, 7245, https://doi.org/10.1002/anie.202014605.

\section{License and Terms}

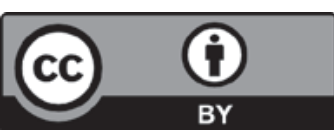

This is an Open Access article under the terms of the Creative Commons Attribution License CC BY 4.0. The material may not be used for commercial purposes.

The license is subject to the CHIMIA terms and conditions: (http:// chimia.ch/component/sppagebuilder/?view=page\&id=12).

The definitive version of this article is the electronic one that can be found at https://doi.org/10.2533/chimia.2021.967 